\title{
Compressed Sugar Coated Caplet Dosage
} Form

National Cancer Institute

\section{Source}

National Cancer Institute. Compressed Sugar Coated Caplet Dosage Form. NCI

Thesaurus. Code C69002.

A tablet that has been compacted into capsule shape and covered in sugar. 